\title{
Research on the Curriculum Reform of College Physical Education
}

\author{
Yuelei Dang ${ }^{1, a}$ \\ ${ }^{1}$ Yulin University, Yulin, Shaanxi,719000 \\ a email
}

Keywords: Physical Education, Curriculum Reform, New Century Development

\begin{abstract}
College Physical Education reform should take the initiative to adapt to the development of basic education and physical education curriculum must train new PE teachers as a starting point and destination, train the talents with knowledge of culture financial knowledge, quality physical education and meet the needs of the community. However, between our various institutions of higher school does combine smoothly with primary school, which also led to disjointed professional training objectives and content of Physical Education and sports school curriculum reform last behind . This paper analyzes the current status of curriculum of physical education and proposal possible reform measures.
\end{abstract}

\section{Introduction}

Currently, many countries are planning or implementation of the cross-century talent training plan, China's sports talent cultivation is also faced with the implementation of cross-century reform. "Century" of Talents of Sports would mean two meanings: the next century, the new century bell one time positioning has sounded: another layer of meaning is the time span of the next century, China's PE teachers training from its creation to the present has been exactly a century, strictly speaking, this layer of meaning of the "century" has not only limited time on the level, the more important it is thought in the sports of higher education, progress and improve other aspects of the theory. If a hundred years ago the basis of socio-economic development of industrial capital and raw materials basis of today's social and economic development that is a hundred years of human capital, the performance of human capital and technological knowledge is the core of economic development. Faced with the challenges of the knowledge economy and in order to improve the quality of education, a center of educational reform in the 21st century has a global expansion. In this global wave of education reform, a particularly noteworthy in common, that is, through the reform of higher education system, personnel training mode and curriculum programs to improve the quality of school resources for improving the quality of education and the key to a breakthrough, but also a Universities fundamental goal of education reform.

\section{College PE Curriculum Status Analysis}

As we all know, it is a professional course of physical presence. Although the higher education sector of sports Current research on PE curriculum more, but mostly confined to the starting point in the surface structure of the course, mainly in: more and less quantitative research qualitative research; research more static and less dynamic research: Stage (now phase) and multi system less and so on. As a special cultural phenomenon, courses are two-layer structure ${ }^{\circ}$ : one is its surface structure, dominated by a certain logic, words, symbols and other standardized information to build up knowledge: another is its deep structure , the performance in maintaining course content logical relationship implies a curriculum subject given its particular value and meaning. PE Teacher Training countries share many common histories, but all aspects of political ideas of countries, economic development, cultural patterns, etc. there is a big difference, and show different characteristics, which will inevitably result in physical education curriculum in countries all levels are different. From the deep structure of the course started, trying to China for other reasons of specialized courses in Physical Education Differences States and explore the world in four higher education institutions, social background, cultural patterns and ideological course, which may help 
is currently in transition variations in the sports curriculum reform of higher education to avoid a repeat of the 1950s' overall imitated Soviet "in the past.

The field of education in the school system is the performance of the basic property relations in the economic field. In Higher Education capitalist social formation dominated Western developed countries, there are two main, one is the representative of the United States where centralized system, the other is Japan between centralism and local representatives stars - right between institutional autonomy. Both management system, although there is a big difference, but the common feature is better planned economy and the market economy will combine the role of government in the development of higher education is positive, it is mainly through economic and legal means this " invisible hand "of the entire higher education macro-control specifications for such personnel, supply and demand, arrange a talent like micro level of specific transaction is managed by the university autonomy according to changes in the job market.

College Sports Professional countries were initially to train physical education teachers in the main, but in general, since the late eighties the world's developed countries, Physical Education Teacher supply and demand has been in excess of state, sports talents steering also contributed to overall PE Curriculum System reform. As China's modern sports budding late, which China and the developed countries turned Sports Talent is still a difference. Developed sports talents steering characteristic two aspects, one tends to be highly educated PE teachers; the second is more diversified demand for sports talents and focus no longer on the physical education teachers in the culture.

Course is a carrier of culture and culture is certainly the most significant part of the curriculum development process is actually a cultural choice. Thus the differences in cultural differences became national sports curriculum structure is one important reason. Marx pointed out that "the different communes in their natural environment, to find a different means of subsistence. Therefore, their mode of production, lifestyles and products will vary." This passage is that the difference between the natural environment. It is a core factor in the formation of national cultural differences. Different national natural geographical environment in which inevitably form their own unique cultural forms. Overall, the cultural patterns of developed countries are mostly Western cultural context, like Japan, Korea and other countries, although belonging to Eastern countries, their cultural influence of traditional culture by China's deep, but Japan, Korea and other countries in the process of absorption of foreign culture in the integration of their national characteristics and pluralistic "cultural coexistence" has become the basic form of the oriental country's culture, is a unique "culture class in Western countries," the inevitable differences cultural patterns have created their own cultural characteristics of curriculum system.

, Europe, Japan and other developed countries are mostly used generalist training mode, which is a notable feature "Fader professional, intensive course." For example, in Japan, when the sixties and seventies, which is usually set only health education university Physical Education in Physical Education, University of Physical Education and Sports Department comprehensive university also set only 3 Bo professional sports. When the demand for social and professional sports talents shift occurs, usually in university courses as a unit react to, that is generally not appropriate immediately set up a new professional social needs, but the first to open a few doors or appropriate new curriculum, which courses are usually set up in the form of elective courses. Only when the new sports career has a very stable job market and the new curriculum development is relatively sound, and has opened a new specialty necessary for teachers, students and the corresponding hardware facilities, before the official opening of a new specialty. Thus its courses, professional, social three are very closely linked. This creates less professional categories, the number of gates and many kinds of courses, professional-caliber wide situation.

\section{The Strategies of Physical Education Curriculum Reform}

Reform of Physical Education Curriculum System The first is to transform education thought. Otherwise, people tend to use the old ideas to explain the new measures, resulting in abortion of the reform or stay on the superficial level. From the sports field of higher education, the "professionals" 
the talent in people's minds is already entrenched, the nascent culture "generalist" Quality Education Thought inevitably produce repellency. Thus, the old ideological education was widely deconstruction and criticism of progressive loss of its authority and guidance functions, new ideas not yet formed, there are still many problems in theory and practice, but also unable to establish its authority and exert its guiding function, this "ideological vacuum" could lead to failure of curriculum reform. Thus, the implementation of Physical Education Curriculum Reform of Physical Thought of Higher Education must change first, under the correct guidance of Physical Education Thought prerequisite to implement curriculum reform tends to be more effective. Educational ideas or concepts mentioned here includes three, ie after pre-vocational education and vocational training and education in Universities in integration, in order to emphasize the overall quality of people-oriented talent and student-centered concept of teaching.

Ignore the "big reform" is an important reason for the "small reform" slow progress. In the past the focus of China's reform of higher education sports, is to improve and optimize the Curriculum System of Physical Education Curriculum Structure, and such variations corresponding micro-level, there is a macro-level changes, namely higher education reform. If the former is mainly related to the professional curriculum reform program is "small reform", then the latter is undoubtedly a "major reform." Over the past few years the "small reform" to change or not change or move slowly, and ignore the "big reform" is very relevant. "The main problem now is the existence of higher education, not a school, a personal question, in the final analysis is the institutional mechanism problem that the institutional problems."

China has five thousand years of splendid culture, there is no lack of advanced education ideas and models, however, many of our educators at every turn, "the burden of thousands of years of traditional culture", not knowing that this "burden" in the number of bears in the world's cultural essence. We should open the "burden", which removed the essence and reject the dross. Secondly, we have "brought" developed advanced ideas and talent training model. Since it is "used", it is to be combined with China's national conditions, to avoid unrealistic completely copy, and do not blindly follow the fashion and novelty, eat "cooked rice." Therefore, the Curriculum Reform of College Physical Education should earnestly implement the "ism", good at summing up experiences and lessons of PE teachers training curriculum development for nearly a century, drawing on theory and practical experience developed similar curriculum development for me Used.

On the one hand, the curriculum reform of PE major health must further advance along a legal track, in other words, regardless of how changes in educational administration, and regardless of how the personnel changes, will be dedicated to exploring the curriculum reform objective laws, follow the objective law, rules to follow, deal with inheritance, the introduction of the reform, innovation and development of the relationship; on the other hand we should establish as soon as possible and improve our higher education system law and sports law, sports higher education development to create a favorable legal environment, the use of this law "invisible hand" managing Physical Education. At the same time, we need to resolutely implement the Education laws and regulations, according to law teaching, according to the law school. In addition, educational administration leadership, the Governing Body is the inter-linkages between curriculum theory and practice of reform, combined with mutual ties and bridges, develop a high level of educational administration management team to establish the role of science cartridge governing body also can not be underestimated, must be included in the legal system construction. Do both leaders, regulatory agencies and there are research, development and evaluation mechanism. Both macro-controls, "national team", there are good local conditions, "the local team." Both professionals, but also is part-time staff. Existing education experts, psychologists, curriculum specialists, subject experts to join, there are experts in various fields and all sectors of society to participate. But relatively stable, perseverance, and make timely adjustments to date.

\section{Conclusion}

Curriculum reform is a core system with a long-term project of the entire higher education. Looking at the development process of the physical education curriculum, to achieve its scientific, 
rationalization and modernization, first of all, we must pay attention to the scientific method and rational strategy. Curriculum reform involves a very wide range impact and is far-reaching. If we adopt inappropriate policies, curriculum reform will be detours and even adverse consequences.

\section{References}

[1] Reber AS. Implicit learning of artificial grammars. Journal of Verbal Learning and Verbal Behavior, 2007

[2] Emmer ET. Classroom management. The Inter national Encyclopedia of teaching and teacher education, 2007

[3] Willam H. Freeman. Physical education and sport in a changing society. Journal of Women s Health, 2001

[4] Horowitz H. L. Campus life: Undergraduate Cultures from the End of the Eighteenth Century to the Present Journal of Women s Health, 1998.

[5] Andrew Brooks. "Harvard Stadium". Harvard University Gazette, 2003 